\title{
Performance of Therapeutic Communication Knowledge Application and Technique during Clinical Training of Nursing College Students
}

\author{
Mi-Young Moon ${ }^{1}$ and Young-Ok Lee ${ }^{2}$ \\ ${ }^{1}$ Department of Nursing, Joongbu University, Korea \\ ${ }^{2}$ Department of Nursing, YEUNGJIN University, Korea \\ ${ }^{1}$ mmy@joongbu.ac.kr, ${ }^{2}$ rose052@yju.ac.kr
}

\begin{abstract}
The objective of this study is to provide the basic data for strengthening the communication learning competency of effective clinical training by understanding the performance of therapeutic communication knowledge application and technique during clinical training of nursing college students. Using the SPSS 21.0 Program for the data analysis, the t-tests and one-way ANOVA were conducted. The performance of therapeutic communication knowledge application and technique showed significant differences in grade, economic condition, and clinical training period. The mean performance of therapeutic communication knowledge application and technique was $1.86 \pm 0.15$ while the problem recognition was the highest and the provision of information was the lowest. In the results of analyzing the factors having effects on the performance of therapeutic communication knowledge application and technique, the grade explained 19.4\%. To strengthen the therapeutic communication competency out of learning strategies of clinical training for nursing college students, the adaptation to the skilled environment and technique would be needed, so it would be necessary to develop the educational intervention program for effective education methods and teaching/learning strategies during clinical training.
\end{abstract}

Keywords: Therapeutic communication, Knowledge application, and technique, Clinical Training, Nursing college students

\section{Introduction}

Therapeutic communication is the nursing activity that could promote interactions between nurse and patient so that the patient could express his/her present condition, goal, treatment, feelings, and health problems related to recovery to the nurse; the nurse could resolve the patient's health problems; the goal of nursing could be achieved [1].

As a nursing technique necessary for approaching and understanding patients from a holistic perspective, therapeutic communication is a professional nursing competency that should be essentially equipped for effectively understanding patients' needs, providing security to patients by helping their problem-solving, and also performing nursing activities for the health enhancement and prevention [2].

Article history:

Received (June 16, 2019), Review Result (August 21, 2019), Accepted (October 8, 2019) 
Thus, it would be necessary to provide more opportunities for learning to experience therapeutic communication to nursing students in nursing education [3]. Also, to provide opportunities for learning to experience therapeutic communication with nursing students, there should be some efforts to develop an effective learning method [4].

To obtain the learning effects of therapeutic communication, the learning methods for acquiring knowledge and attitude in the psychomotor, cognitive, and affective domains should be all considered. Therefore, it is needed to have a learning method that could provide extensive experiential opportunities to be able to learn a specific technique and attitude of therapeutic communication, instead of simple delivery of knowledge through lectures [5].

Thus, the researcher aims to provide the basic data for strengthening the therapeutic communication learning competency in the clinical training education of the actual clinical condition, by understanding the performance of therapeutic communication knowledge application and technique between nursing students and their case subjects in the actual clinical condition during clinical training and also understanding the factors having effects out of the relevant characteristics.

\section{Methods}

\subsection{Participants and data collection}

This study selected Grades $3 \& 4$ of nursing college students who completed clinical training for two weeks or more in two universities located in K province and D metropolitan city through convenience sampling. In the results of using the $G$ power 3.1 software (Mindspark Interactive Network). to calculate the proper number of samples, with the significance level $(\alpha) .05$, power(1- $\beta$ ).95, effect size(r).15(middle), and 14 predicting variables, the minimum sample size necessary for the multiple regression analysis was calculated as 194. Considering the $10 \%$ drop-out rate, the questionnaires were distributed to 275 people through convenience sampling. Out of the collected 251 questionnaires, a total of 235 respondents(93.5\%) were selected as the research subjects after excluding 16 questionnaires $(6.5 \%)$ with insufficient responses.

\subsection{Research tools}

The performance of therapeutic communication knowledge application and technique was developed by Lee [7] to evaluate the performance degree of therapeutic communication of nursing students by directly observing the process of applying the therapeutic communication technique to standardized patients. This study used one for students, which was composed of a total of 15 items for measuring the degree of therapeutic communication knowledge and technique, three items for measuring the perception of the nursing problem, and one item for measuring the satisfaction with the overall therapeutic communication application. In the measurement, two points were given to 'Yes', and one point was given to 'No'. Based on the score range from a minimum of 15 to a maximum of 30, when the score was higher, the performance of therapeutic communication knowledge application and technique was high. In this study, Cronbach's alpha was .778.

\subsection{Data analysis}

The collected data was analyzed by using the SPSS 21.0 program. The general characteristics of nursing college students and the performance of therapeutic communication 
knowledge application and technique were analyzed by using the percentage, mean, and standard deviation. The differences in the general characteristics of nursing college students and the performance of therapeutic communication knowledge application and technique were analyzed by using the t-test, ANOVA, and Scheffe. The effects on the therapeutic communication knowledge application and technique of nursing college students were analyzed by using the multiple linear regression analysis.

\section{Results}

\subsection{Measurement tools of the performance of therapeutic communication knowledge application and technique by the general characteristics of subjects}

In this study, the differences in the general characteristics of subjects, and the measurement tools of the performance of therapeutic communication knowledge application and technique by the general characteristics are as follows. In the general characteristics, out of the subjects, the women $(80 \%)$ and the 'middle rank' of the school record $(54.9 \%)$ were the most. The clinical training period was two weeks (31.9\%) - 19 weeks $(23 \%)$. The performance of therapeutic communication knowledge application and technique by the general characteristics of subjects showed significant differences in grade $(\mathrm{p}<.001)$, economic condition $(\mathrm{p}=.047)$, and clinical training period $(\mathrm{p}<.001)$ [Table 1].

\subsection{Performance of therapeutic communication knowledge application and technique of subjects}

The performance of therapeutic communication knowledge application and technique of subjects was $1.86 \pm 0.15$ [Table 2].

Table 1. The therapeutic communication knowledge application and technique by the general characteristics $(\mathrm{N}=235)$

\begin{tabular}{|c|c|c|c|c|}
\hline & \multirow[t]{2}{*}{ - } & \multirow{2}{*}{$\mathrm{N}(\%)$} & \multicolumn{2}{|c|}{$\begin{array}{c}\text { Therapeutic Communication Knowledge } \\
\text { Application and Technique }\end{array}$} \\
\hline & & & mean \pm sd & t or F (p) \\
\hline \multirow{2}{*}{ Gender } & Men & $47(20.0)$ & $1.83 \pm 0.19$ & \multirow{2}{*}{$\begin{array}{r}-1.384 \\
(.168)\end{array}$} \\
\hline & Women & $188(80.0)$ & $1.86 \pm 0.14$ & \\
\hline \multirow{2}{*}{ Grade } & Grade 3 & $180(76.6)$ & $1.83 \pm 0.16$ & \multirow{2}{*}{$\begin{array}{r}-5.038 \\
(.000)\end{array}$} \\
\hline & Grade 4 & $55(23.4)$ & $1.95 \pm 0.08$ & \\
\hline \multirow{3}{*}{ School Record* } & High(top 30\%) ${ }^{\mathrm{a}}$ & $60(25.5)$ & $1.88 \pm 0.14$ & \multirow{3}{*}{$\begin{array}{l}1.846 \\
(.160)\end{array}$} \\
\hline & Middle $^{\mathrm{b}}$ & $129(54.9)$ & $1.84 \pm 0.16$ & \\
\hline & Low(bottom $30 \%)^{c}$ & $46(19.6)$ & $1.87 \pm 0.12$ & \\
\hline \multirow{4}{*}{ Religion } & Christianity & $41(17.4)$ & $1.86 \pm 0.15$ & \multirow{4}{*}{$\begin{array}{l}2.239 \\
(.084)\end{array}$} \\
\hline & Buddhism & $20(8.5)$ & $1.78 \pm 0.20$ & \\
\hline & Catholicism & $24(10.2)$ & $1.83 \pm 0.19$ & \\
\hline & None & $150(63.8)$ & $1.87 \pm 0.13$ & \\
\hline \multirow{3}{*}{$\begin{array}{l}\text { Economic } \\
\text { Condition }\end{array}$} & $\operatorname{High}^{\mathrm{a}}$ & $17(7.2)$ & $1.90 \pm 0.15$ & \multirow{3}{*}{$\begin{array}{l}3.095 \\
(.047)\end{array}$} \\
\hline & Middle $^{\mathrm{b}}$ & $196(83.4)$ & $1.85 \pm 0.15$ & \\
\hline & Low $^{c}$ & $22(9.4)$ & $1.92 \pm 0.09$ & \\
\hline Major Life & Very satisfied & $14(6.0)$ & $1.86 \pm 0.16$ & 0.676 \\
\hline
\end{tabular}


Performance of Therapeutic Communication Knowledge Application and Technique During Clinical Training of Nursing College Students

\begin{tabular}{|c|c|c|c|c|}
\hline \multirow[t]{3}{*}{ Satisfaction } & Satisfied & $98(41.7)$ & $1.84 \pm 0.18$ & \multirow[t]{3}{*}{$(.567)$} \\
\hline & Average & $109(46.4)$ & $1.87 \pm 0.12$ & \\
\hline & Dissatisfied & $14(6.0)$ & $1.86 \pm 0.17$ & \\
\hline \multirow{3}{*}{$\begin{array}{c}\text { Scholastic } \\
\text { Achievement Level* }\end{array}$} & Excellent $^{\mathrm{a}}$ & $11(4.7)$ & $1.83 \pm 0.23$ & \multirow{3}{*}{$\begin{array}{l}1.222 \\
(.296)\end{array}$} \\
\hline & Satisfactory $^{\mathrm{b}}$ & $112(47.7)$ & $1.87 \pm 0.15$ & \\
\hline & Insufficient $^{c}$ & $112(47.7)$ & $1.84 \pm 0.15$ & \\
\hline \multirow{2}{*}{$\begin{array}{c}\text { Experience in Taking } \\
\text { Communication } \\
\text { Courses }\end{array}$} & Yes & 230(97.9) & $1.86 \pm 0.15$ & \multirow{2}{*}{$\begin{array}{l}0.707 \\
(.480)\end{array}$} \\
\hline & No & $5(2.1)$ & $1.81 \pm 0.10$ & \\
\hline \multirow{6}{*}{$\begin{array}{l}\text { Clinical Training } \\
\text { Period }^{*}\end{array}$} & 2 weeks $^{a}$ & $75(31.9)$ & $1.83 \pm 0.14$ & \multirow{6}{*}{$\begin{array}{c}6.537 \\
(.000) \\
(a, b, e<f)\end{array}$} \\
\hline & 4 weeks $^{\mathrm{b}}$ & $23(9.8)$ & $1.80 \pm 0.17$ & \\
\hline & 6 weeks $^{\mathrm{c}}$ & $40(17.0)$ & $1.86 \pm 0.15$ & \\
\hline & 8 weeks $^{\mathrm{d}}$ & $21(8.9)$ & $1.85 \pm 0.14$ & \\
\hline & 10 weeks $^{\mathrm{e}}$ & $21(8.9)$ & $1.77 \pm 0.21$ & \\
\hline & 19 weeks $^{f}$ & $55(23.4)$ & $1.95 \pm 0.08$ & \\
\hline \multirow{3}{*}{$\begin{array}{l}\text { The aspect of Family } \\
\text { Communication }\end{array}$} & $\begin{array}{l}\text { Order-oriented } \\
\text { communication }\end{array}$ & $7(3.0)$ & $1.91 \pm 0.14$ & \multirow{3}{*}{$\begin{array}{l}0.417 \\
(.660)\end{array}$} \\
\hline & $\begin{array}{c}\text { Position-oriented } \\
\text { communication }\end{array}$ & $40(17.0)$ & $1.85 \pm 0.14$ & \\
\hline & $\begin{array}{l}\text { Character-oriented } \\
\text { communication }\end{array}$ & $288(80.0)$ & $1.86 \pm 0.15$ & \\
\hline
\end{tabular}

Table 2. Performance of therapeutic communication knowledge application and technique of subjects $(\mathrm{N}=235)$

\begin{tabular}{|c|c|c|c|}
\hline Contents & Item & content & mean \pm sd \\
\hline \multirow{3}{*}{$\begin{array}{l}\text { Problem } \\
\text { Recognition }\end{array}$} & 1 & $\begin{array}{l}\text { Recognized and observed the patient's facial expression of } \\
\text { concern }\end{array}$ & $1.97 \pm 0.18$ \\
\hline & 2 & Asked questions one by one efficiently & $1.97 \pm 0.15$ \\
\hline & 3 & Listened to the patient without cutting his/her words & $1.97 \pm 0.15$ \\
\hline Openness & 4 & Used appropriate open-ended and close-ended questions & $1.88 \pm 0.32$ \\
\hline $\begin{array}{l}\text { Active } \\
\text { Listening }\end{array}$ & 5 & $\begin{array}{l}\text { Listened actively to understand the patient's concerns and } \\
\text { feelings }\end{array}$ & $1.94 \pm 0.23$ \\
\hline Empathy & 6 & Expressed empathy for the patient's concerns and feelings & $1.97 \pm 0.18$ \\
\hline Focusing & 7 & Helped patient to continue and finish his/her question & $1.89 \pm 0.31$ \\
\hline Encouraging & 8 & Encouraged patient to express his/her concerns and feelings & $1.96 \pm 0.19$ \\
\hline $\begin{array}{l}\text { Using } \\
\text { Silence }\end{array}$ & 9 & Quietly wait for the patient's response & $1.94 \pm 0.20$ \\
\hline \multirow{2}{*}{ Summarizing } & 10 & Asked if the patient understood the information provided & $1.96 \pm 0.18$ \\
\hline & 11 & Provided opportunities for the patient to ask questions & $1.68 \pm 0.46$ \\
\hline \multirow{3}{*}{$\begin{array}{l}\text { Providing } \\
\text { Information }\end{array}$} & 12 & Educated on PCA pain management & $1.85 \pm 0.36$ \\
\hline & 13 & Educated on dietary therapy after surgery & $1.56 \pm 0.49$ \\
\hline & 14 & $\begin{array}{c}\text { Explained simply and specifically to address patient's } \\
\text { questions avoiding jargon }\end{array}$ & $1.56 \pm 0.49$ \\
\hline Satisfaction & 15 & $\begin{array}{l}\text { Satisfied with the overall use of therapeutic communication } \\
\text { techniques }\end{array}$ & $1.82 \pm 0.38$ \\
\hline Total & & \multicolumn{2}{|l|}{$1.86 \pm 0.15$} \\
\hline
\end{tabular}




\subsection{Factors having effects on the therapeutic communication knowledge application and technique of subjects}

In the results of analyzing the statistically significant variables $(\mathrm{p}<.05)$ in the general characteristics of subjects and the factors having effects on the therapeutic communication knowledge application and technique, the grade explained $19.4 \%(\mathrm{~F}=19.451, \mathrm{p}<.001)$. When the grade was higher $(\beta=.473, \mathrm{p}=.001)$, the performance of therapeutic communication knowledge application and technique was high [Table 3].

Table 3. Factors having effects on the therapeutic communication knowledge application and technique of subjects $(\mathrm{N}=253)$

\begin{tabular}{|c|c|c|c|c|c|c|c|}
\hline \multicolumn{2}{|r|}{ - } & - & $\mathrm{B}$ & $\beta$ & $t(p)$ & $\mathrm{R}$ & Adjusted R2 \\
\hline \multirow{4}{*}{$\begin{array}{l}\text { Therapeutic } \\
\text { Communication } \\
\text { Knowledge } \\
\text { Application and } \\
\text { Technique }\end{array}$} & Constant & .919 & & $8.328(.000)$ & \multirow{4}{*}{.546} & \multirow{4}{*}{283} & \multirow{4}{*}{$\begin{array}{c}19.451 \\
(.000)\end{array}$} \\
\hline & Grade & .174 & .473 & $3.250(.001)$ & & & \\
\hline & Economic Condition & .026 & .067 & $1.182(.238)$ & & & \\
\hline & Clinical Training Period & -.005 & -.214 & $-1.465(.144)$ & & & \\
\hline
\end{tabular}

\section{Discussion}

This study understood the performance of therapeutic communication knowledge application and technique in the actual clinical condition, and also analyzed the relevant factors, targeting Grades $3 \& 4$ of nursing college students with experiences in clinical training.

Viewing the performance of therapeutic communication knowledge application and technique of subjects of this study, there were significant differences in grade $(\mathrm{p}<.000)$, economic condition $(\mathrm{p}=.047)$, and clinical training period $(\mathrm{p}<.001)$ by the general characteristics. Regarding the grade, Grade 4 was higher than Grade 3. In the clinical training period, the students who performed the 19 week-training periods showed the highest. The actual application of therapeutic communication to patients in clinical conditions should be based on lots of training experiences of nursing college students.

A thesis on the performance of therapeutic communication knowledge application and technique is a part. Lee [6] evaluated the performance of therapeutic communication knowledge application and technique in the simulation class applying the standardized patient scenario, in the division of professors, standardized patients, and students. This study evaluated it during clinical training for patients in the actual clinical condition, instead of an imaginary condition, which is the difference. In the results of the performance of therapeutic communication knowledge application and technique, in the research by Lee [6], items No. 1

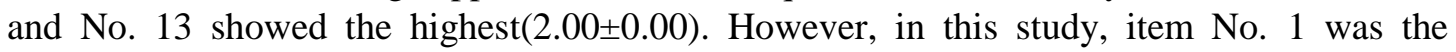
highest $(1.97 \pm 0.18)$ while No. 13 was the lowest $(1.56 \pm 0.49)$. Item No. 13 was about 'postsurgery dietary education for surgical patients'. This result must be originated from the fact that there were not many hospitalized surgical patient cases in the actual clinical condition. In the future, it would be necessary to have the additional intervention of variables considering the current clinical condition, and also to have the analysis of the results considering the ward for training.

The grade was the factor having effected the performance of therapeutic communication knowledge application and technique. Because Grade 4 showed a higher application of 
technical performance than Grade 3, the skilled technique and adaptation to the environment could be considered as the educational environment necessary for performing the therapeutic communication knowledge and technique.

\section{Conclusion and suggestions}

For the adaptation of therapeutic communication to the clinical environment, there should be a place for environmental education in which the skilled knowledge and technique of therapeutic communication could be learned. For this, it would be necessary to develop a teaching/learning strategic program.

\section{Acknowledgments}

It is considered that cooperative systems must be established continuously through the development of a cooperative management program between the university and the nursing department.

\section{References}

[1] Ruth F. C. and Constance J. H., "Fundamentals of nursing: human health and function (5th Ed)," Philadelphia, Lippincott Williams \& Wilkins, (2007)

[2] Im S. B., Kim D. H., Bae J. Y., Kim H. S., Son H. M., Park K. H., and Park Y. S., "Nursing practice communication," Seoul: Elsevier Korea, (2012)

[3] Bolstad A. L., Xu Y., Shen J. J., Covelli M., and Torpey M., "Reliability of standardized patients used in a communication study on international nurses in the United States of America," Nursing \& Health Sciences, vol.14, no.1, pp.67-73, (2012) DOI: 10.1111/j.1442-2018.2011.00667.x

[4] Park S. Y., "The effect of using standardized patients in psychiatric nursing practical training for nursing college students," Gwangju: Graduate School, Chosun University, (2012)

[5] Suh E. Y., "Development of a conceptual framework for nursing simulation education utilizing human patient simulators and standardized patients," The Journal of Korean academic society of nursing education, vol.18, no.2, pp.206-219, (2012) DOI: 10.5977/jkasne.2012.18.2.206

[6] Basaran A, Emre U, Karadavut KI, Balbaloglu O, and Bulmus N., "Hand splinting for poststroke spasticity: A randomized controlled trial," Topics in Stroke Rehabilitation, vol.19, no.4, pp.329-337, (2012) DOI: 10.1310/tsr1904-329

[7] Yan T. and Hui-Chan CW., "Transcutaneous electrical stimulation on acupuncture points improves muscle function in subjects after acute stroke: A randomized controlled trial," Journal of Rehabilitation Medicine, vol.41, no.5, pp.312-316, (2009) DOI: 10.2340/16501977-0325 